\title{
Electrophysiologic Characteristics of Ventricular Arrhythmias Arising From the Aortic Mitral Continuity - Potential Role of the Conduction System
}

\author{
Jo Jo Hai, MBBS ${ }^{1}$, Anwar A. Chahal ${ }^{1}$, Paul A. Friedman ${ }^{1}$, Vaibhav R. Vaidya ${ }^{1}$, Faisal F. \\ Syed $^{1}$, Christopher V. DeSimone, MD, PhD ${ }^{1}$, Sudip Nanda, M.D., Peter A. Brady ${ }^{1}$, Malini \\ Madhavan, M.D., Yong-Mei Cha ${ }^{1}$, Christopher J. McLeod ${ }^{1}$, Siva Mulpuru' ${ }^{1}$, Thomas M. \\ Munger $^{1}$, Douglas L. Packer ${ }^{1}$, and Samuel J. Asirvatham, $\mathbf{M D}^{1,2}$ \\ ${ }^{1}$ Division of Cardiovascular Diseases, Mayo Clinic, Rochester, MN; Department of Internal \\ Medicine, Mayo Clinic, Rochester, MN \\ ${ }^{2}$ Department of Pediatrics and Adolescent Medicine Mayo Clinic, Rochester, MN
}

\begin{abstract}
Introduction-Catheter ablation of ventricular arrhythmia (VA) at the fibrous aortic mitral continuity (AMC) has been described, yet the nature of the arrhythmogenic substrate remains unknown.
\end{abstract}

Methods-Procedural records of 528 consecutive patients undergoing ablation of VA at Mayo Clinic, Rochester, MN, were reviewed. The electrocardiographic and electrophysiologic characteristics of patients with successful ablation at the AMC were analyzed to characterize the underlying arrhythmogenic substrate.

Results-Of the 21 patients (mean age $53.2 \pm 13.4$ years, $47.6 \%$ male) who underwent ablation of VA at the AMC with acute success, prepotentials (PPs) were found at the ablation sites preceding the ventricular electrogram (VEGM) during arrhythmias in $13(61.9 \%)$ patients and during sinus rhythm in 7 (53.8\%) patients. VAs with PPs were associated with a significantly higher burden of premature ventricular complexes (PVCs) $(26.1 \pm 10.9 \%$ vs $14.9 \pm 10.1 \%, \mathrm{p}=$ $0.03)$, shorter VEGM to QRS intervals $(9.0 \pm 28.5 \mathrm{~ms}$ vs $33.1 \pm 8.8 \mathrm{~ms}, \mathrm{p}=0.03)$, lower pace map scores $(8.7 \pm 1.6$ vs $11.4 \pm 0.8, \mathrm{p}=0.001)$, and a trend towards shorter $\mathrm{V}-\mathrm{H}$ intervals during VA $(32.1 \pm 38.6 \mathrm{~ms}$ vs $76.3 \pm 11.1 \mathrm{~ms}, \mathrm{p}=0.06)$ as compared to those without PP. A strong and positive correlation was found between V-H interval and QRS duration during arrhythmia in those with PPs $\left(B=2.11, R^{2}=0.97, t=13.7, p<0.001\right)$ but not in those without PPs.

Conclusion-Local EGM characteristics and relative activation time of the His bundle suggest the possibility of conduction tissue as the origin for VA arising from the fibrous AMC. Specific identification and targeting of PPs when ablating VAs at this location may improve procedural success.

Corresponding Author: Samuel J. Asirvatham, MD, Division of Cardiovascular Diseases and Department of Pediatrics and Adolescent Medicine Mayo Clinic, Rochester, MN, 200 First Street SW, Rochester, MN 55905, Tel: 507-283-3376, Fax: 507-255-2440, asirvatham.samuel@mayo.ed. Other authors: No disclosures. 


\section{Keywords}

ventricular arrhythmias; aortomitral continuity; conduction system; arrhythmogenic substrate

\section{Introduction}

The aortic mitral continuity (AMC) is a fibrous structure embedded between the aortic and mitral annuli. Although successful ablations of arrhythmias at the AMC have been reported in the literature, ${ }^{1-12}$ knowledge of the clinical, electrocardiographic (ECG), and electrophysiological characteristics of idiopathic ventricular arrhythmias (VAs) arising from this region remains limited. Furthermore, being a fibrous structure, the exact nature of the arrhythmogenic substrate remains unclear. ${ }^{4,13-17}$ To improve our understanding of this relatively uncommon arrhythmia, we retrospectively reviewed and described the clinical, ECG, and electrophysiological characteristics of idiopathic VAs successfully ablated at the AMC in our institution.

\section{Methods}

\section{Patients}

This study was approved by the Institutional Review Board of Mayo Clinic, Rochester, MN. Five hundred and twenty-eight patients who underwent ablation of idiopathic VA at Mayo Clinic from 2002 to 2012 were retrospectively reviewed. All patients provided informed consent before their procedure. Twenty-one patients with definitive ablation at the AMC, as confirmed by fluoroscopy and intracardiac echocardiography as stated in the procedural reports, were identified. All patients had either spontaneously present or inducible VAs, which allowed detailed mapping.

\section{Electrophysiology study and ablation}

Antiarrhythmic drugs were withheld for at least five half-lives, and amiodarone was withheld for at least 2 weeks prior to the procedure. All procedures were performed under conscious sedation with propofol and fentanyl. Multipolar catheters were inserted percutaneously via the right internal jugular and the common femoral veins and were positioned in the right atrium, right ventricle, coronary sinus, and the His bundle region. Bipolar electrograms (EGMs) were filtered with a bandpass of 30 to $500 \mathrm{~Hz}$ and displayed on a digital recording system (Prucka Engineering, Inc., Houston, TX, USA). VAs were induced by atrial or ventricular burst pacing or programmed stimulation as appropriate. Isoproterenol or epinephrine infusion was given when needed. The mechanisms of arrhythmias were defined based on the methods of induction and response to pacing maneuvers. ${ }^{18-26}$ A 7.5-Fr, 3.5-mm, open- or non-irrigated tip catheter was advanced to the left ventricle via the retrograde aortic approach or through transseptal puncture to map and ablate the VAs. Electroanatomical mapping was performed by means of a 3-dimensional mapping system (CARTO, Biosense Webster, Inc., Diamond Bar, CA, USA). During ablation, the earliest local EGMs or prepotentials (PPs) were targeted for focal VAs, ${ }^{26}$ and the critical isthmuses were targeted for reentrant VAs. ${ }^{25-27}$ Radiofrequency energy was delivered at each site for 60 to 120 seconds with the power output capped at 25 to $40 \mathrm{~W}$. 
Catheter position was confirmed by fluoroscopy and intracardiac echocardiography. Acute success was defined as non-inducibility by pacing maneuvers or infusion of adrenergic agents at the end of the procedure.

\section{Electrocardiography}

VAs targeted during procedures were reviewed offline with our digital recording system. Twelve-lead ECGs were interpreted at a sweep speed of $100 \mathrm{~mm} / \mathrm{s}$ and amplitude of 10 $\mathrm{mm} / \mathrm{mV}$. All ECG analyses were performed according to standard criteria by a single cardiologist blinded to the procedural findings. ${ }^{28-30}$

\section{Intracardiac electrograms}

Intracardiac EGMs were reviewed on our digital recording system. The V-H interval was defined as the shortest measurable interval from the onset of surface QRS to the His deflection during VA. Local ventricular EGM (VEGM) to QRS interval was measured from the point of maximal deflection (dV/dt) of the bipolar EGM to the onset of the surface QRS. ${ }^{31} \mathrm{PP}$ was defined as a discrete sharp deflection ahead of and separated from the VEGM by an isoelectric segment of more than $5 \mathrm{~ms} .{ }^{32,33}$ When the PP was identified, PPQRS and PP-VEGM intervals were also assessed.

\section{Statistical Analysis}

Continuous variables were reported as mean \pm standard deviation. Categorical variables were presented in frequency tables. Statistical comparisons were performed using a 2-tailed student's t-test or Wilcoxon rank sum test for continuous variables, and Pearson Chi-square test or Fisher exact test for categorical variables, as appropriate. Relationships between the $\mathrm{V}-\mathrm{H}$ interval and QRS duration were calculated using a linear regression model. P values of $<0.05$ were considered statistically significant. All analyses were performed using SPSS software (version 21.0, SPSS, Inc., Chicago, IL, USA).

\section{Results}

\section{Clinical characteristics}

Twenty-one patients who had VAs successfully ablated at the AMC were included in this study. The mean age of the patients was $53.2 \pm 13.4$ years, with $10(47.6 \%)$ of them male. Seven $(33.3 \%)$ patients had a left ventricular ejection fraction (LVEF) of $\mathbf{5 0 \%}$ before ablation. The most common presentation was symptomatic PVCs $(n=16,76.2 \%)$. Other presentations included heart failure $(\mathrm{n}=2,9.5 \%)$, symptomatic ventricular tachycardia (VT, $\mathrm{n}=1,4.8 \%)$, and PVC-triggered ventricular fibrillation ( $\mathrm{n}=3,14.3 \%)$. Prior to ablation, Holter recordings and exercise testing documented PVCs in all (100\%), non-sustained VT in $9(42.9 \%)$, and sustained VT in $2(9.5 \%)$ patients. At a mean follow-up duration of $12.7 \pm$ 12.8 months, PVC burden was significantly reduced from $23.4 \pm 13.1 \%$ to $2.2 \pm 3.4 \%$ (p $<0.001$, Table 1). All symptoms except syncope improved at follow-up (all $\mathrm{p}<0.05$, Table 1). Three patients who had initial left ventricular dysfunction demonstrated improvement of LVEF to $>50 \%$ after ablation. 


\section{Prepotentials}

PPs were found at the successful ablation site in 13 (61.9\%) patients (Figure 1, Panel A). The mean PP-VEGM and the PP-QRS intervals during VAs were $65.7 \pm 34.1 \mathrm{~ms}$ and $73.7 \pm$ $23.6 \mathrm{~ms}$, respectively. PPs were seen ahead of VEGMs during sinus rhythm in 7 (53.8\%) patients. Patients with PPs had a significantly higher PVC burden before ablation than those without PPs $(26.1 \pm 10.9 \%$ vs $14.9 \pm 10.1 \%, \mathrm{p}=0.03$, Table 2$)$. Nevertheless, there was no significant difference in patients' demographics, clinical presentations, types of VAs, and echocardiographic findings between those with and without PPs (all p >0.05, Table 2). Multiple VA morphologies were found in 4 patients with PPs but none in those without PP, although the difference did not reach statistical significance $(p>0.05$, Table 2$)$.

\section{Electrocardiographic characteristics}

ECG characteristics of VAs with and without PPs are presented in Table 3. A total of 25 VAs were analyzed. The mean QRS duration of VAs was $145.2 \pm 16.9 \mathrm{~ms}$ in those with PPs and $151.3 \pm 21.3 \mathrm{~ms}$ in those without PP $(\mathrm{p}=0.45)$. Tall $\mathrm{R}$ waves were observed over the inferior leads in all VAs and right axis deviation in $15(60 \%)$ of the VAs. Left bundle branch block morphology was seen only in VA with PP $(\mathrm{n}=6,35.3 \%)$ but not VA without PP ( $\mathrm{p}=$ 0.13). Among those VAs associated with PP, 6 (35.3\%) demonstrated precordial transition $>$ V1, 4 (23.5\%) had Q waves in V1, 3 (17.6\%) had RSR' pattern in V1, and $5(29.4 \%)$ had deep $\mathrm{S}$ waves in V2. On the other hand, Q wave in V1 was seen only in 1 VA without PP (case 4, Table 3), while RSR' in V1, deep S wave at V2, and precordial transition demonstrating a rebound pattern ${ }^{2}$ was found in another VA without PP (case 11, Table 3); though these differences did not reach statistical significance.

\section{Electrophysiological characteristics}

VAs were induced by atrial or ventricular burst pacing in 8 out of 21 patients and infusion of adrenergic agents in 9 out of 17 patients, while none were induced by programmed electrical stimulation. Among the 13 patients with PPs, the earliest VEGMs were located at the AMC in $9(69.2 \%)$, at the junction between the great cardiac vein and the anterior interventricular vein (GCV-AIVV) in 3 (23.1\%), and near the left coronary artery in 1 (7.7\%). In 2 patients who had the earliest VEGM found at the GCV-AIVV, ablation failed to eliminate the VAs, and thus the electrophysiologists re-mapped the entire region and found the PPs consistently preceding the VAs at the AMC. Ablation of the PPs then successfully eliminated the VAs. For the other 2 patients, the electrophysiologist found the PPs at the AMC during initial mapping and elected to target the PPs instead of the sites of the earliest VEGM. Among the 8 patients without PP, the earliest VEGMs were found at the AMC in $6(75 \%)$ and GCVAIVV in $2(25 \%)$. Ablations were attempted at the GCV-AIVV in both cases. However, due to failure of power delivery, the electrophysiologists elected to ablate endocardially at the AMC, which successfully eliminated the VAs.

The mean VEGM-QRS duration at the successful ablation sites at the AMC was significantly shorter $(9.0 \pm 28.5 \mathrm{~ms}$ vs $33.1 \pm 8.8 \mathrm{~ms}, \mathrm{p}=0.03)$, and the pace map scores were significantly lower $(8.7 \pm 1.6$ vs $11.4 \pm 0.8, \mathrm{p}=0.001)$ in those with than without PPs (Table 2). Ablations were associated with monomorphic VT in $8(61.5 \%)$ patients with PPs 
and $3(37.5 \%)$ without PP $(\mathrm{p}=1.0)$, and none of them had polymorphic VT or ventricular fibrillation during the procedure.

His signal was clearly seen during VAs in 7 patients with PPs and 4 without PPs. VAs with PPs demonstrated a trend towards a shorter V-H interval as compared to those without PPs $(32.1 \pm 38.6 \mathrm{~ms}$ vs $76.3 \pm 11.1 \mathrm{~ms}, \mathrm{P}=0.06$, Table 2, Figure 1, Panel B). A strong and positive correlation existed between the V-H interval and QRS duration of VAs with PPs (B $=2.11, \mathrm{R}^{2}=0.97, \mathrm{t}=13.7, \mathrm{p}<0.001$, Figure 2), but not in those without PP.

\section{Discussion}

Of the 21 patients who had successful ablation of VAs at the AMC, PPs were found in 13 (61.9\%) of them. Patients who had PPs had a higher PVC burden, and they tended to have multiple VA morphologies and shorter V-H intervals. The VEGM-QRS intervals at the successful ablation sites were significantly shorter, and the pace map scores were significantly lower in those with PPs as compared to those without PPs. In addition, a strong and positive correlation existed between the V-H interval and QRS duration among those with PPs. In the remaining 8 cases no PPs were identified at the sites of successful ablation.

\section{Prepotentials}

PP was defined as a discrete sharp deflection that preceded and was separated from the VEGM by an isoelectric segment. ${ }^{31,33}$ A previous study in 10 patients who had VAs ablated at the AMC by Chen et al. found similar PPs in 4 of them, although the exact mechanism was not clarified. ${ }^{2}$ In this study, we demonstrated a strongly positive association between the V-H interval and the QRS duration during VA, which suggested that these PPs were likely associated with involvement and activation of conduction tissue.

As the His-Purkinje system is a branching structure, ${ }^{34}$ the anterograde wavefront of VA arising from the proximal conduction system simultaneously activates multiple portions of the ventricular myocardium, leading to a narrow QRS complex, while the retrograde wavefront rapidly reaches the His bundle, giving rise to a short V-H interval. On the contrary, the anterograde wavefront of VA arising from the distal conduction system activates only a limited region of the left ventricle, leading to a wide QRS complex, while it takes longer for the retrograde wavefront to activate the His bundle, giving rise to a long V$\mathrm{H}$ interval. Although similar relationship can also be found with VAs originating from ventricular muscle cells at the Purkinje-myocardial interface, wherein the passively involved conduction system gives rise to the PPs, this is less likely given that previous anatomical studies have failed to find any myocardium in this region.

\section{Electrocardiographic Characteristics}

Previous studies on the ECG characteristics of VAs originating from the AMC have yielded inconsistent results. $2,3,6,7,12$ Chen et al. attempted to explain these differences by dividing the AMC into anterior and mid portions. ${ }^{2}$ They have shown that all VAs originating from the anterior AMC have a left bundle branch block pattern and precordial transition $\leq \mathrm{V} 2$, whereas VAs originating from the mid AMC have a right bundle branch block pattern, and rebound transition pattern is commonly seen. ${ }^{2}$ However, this does not explain the variable 
appearance of Q waves in V1 and S waves in some of the precordial leads. ${ }^{2}$ In our study, we found that the QRS morphologies appeared to be more variable in VAs associated with PPs than those without PPs. These included the presence of left bundle branch morphology, Q waves in V1, deep S waves in V2, and precordial transition >V1. Furthermore, multiple QRS morphologies arising from the same arrhythmic focus were also seen in those VAs associated with PPs. Although the exact mechanism remains unknown, one possible explanation for the variable QRS morphologies found in this study, as well as the previous ones, could be due to variable involvement of and exit from the His-Purkinje system, either actively or passively.

\section{Possible arrhythmogenic substrate}

Although successful ablation of arrhythmias at the AMC has been described, ${ }^{1-12}$ the exact nature of the arrhythmogenic substrate remains unknown. ${ }^{4,13-17}$ While no myocardium has been found in this region, animal studies have shown that cells with electrophysiological properties similar to that of the atrioventricular (AV) junctional cells are present near the mitral annulus. ${ }^{35,36}$ During embryonic development, specialized conduction tissue encircles both AV orifices, including the fibrous AMC. ${ }^{4,} 37$ This ring of conduction tissue matures into the left and right bundle branches, as well as a third septal branch that normally regresses at the later stage. ${ }^{16,34}$ Studies have suggested that AV junctional tissue that fails to regress can become arrhythmogenic later in life. ${ }^{4,16,36,38}$ Furthermore, depending on their connection with the atrium, ventricle, and various parts of the normal conduction system including the AV node, bundle branches, and fascicles, arrhythmias associated with remnant conduction tissues at the AMC may have different ECG and electrophysiological manifestations. ${ }^{4,} 16,35,36$

To our knowledge, no anatomical study has demonstrated the presence of ventricular muscle in the AMC. While our findings do not refute this possibility, it is plausible that isolated cells from the degenerated conduction system give rise to these VAs. Another possibility is that the AMC only acts as a vantage point for ablation of epicardial arrhythmic foci. Unfortunately, none of these possibilities can be easily proven in human studies.

\section{Limitations}

This study had a small sample size, and thus statistical significance was not reached in most of the electrocardiographic parameters despite an apparent difference in prevalence. In addition, induction and pacing maneuvers were not performed systematically in all patients due to technical difficulties or the individual electrophysiologists' preferences. This led to difficulty in delineating the mechanism of VA in 3 patients. Furthermore, the V-H interval could not be discerned in 10 patients without PP, possibly due to the close proximity of the His signal and the VEGM. Nevertheless, the strong and positive correlation between the V$\mathrm{H}$ intervals and the QRS duration in those with PP remained. Lastly, there are several potential reasons for a change in the local ventricular electrogram, which include differential movement of the mapping catheter relevant to the fibrous AMC, different wavefront of activation of the ventricular myocardium during the PVC versus conducted sinus beats, or loss of catheter contact. Multiple mechanisms of arrhythmia may have been operative in these patients, including peri-AMC myocardium or Purkinje origin that could not be 
distinguished from true AMC origin despite real-time intracardiac ultrasound echocardiographic evaluation. Despite these possibilities, we have shown that the site of ablation was verified by intracardiac echo and ablation eliminated VA at this site, making these potential alternative explanations unlikely.

\section{Conclusion}

We present the clinical, ECG, and electrophysiological characteristics of a series of patients who had VAs successfully ablated at the AMC. In particular, PPs were targeted for successful ablation in over half of the patients. When ablation at sites with the earliest VEGM and best pace map score, which represents the exit site, does not eliminate the arrhythmia, detailed mapping to identify and target the earliest PP may improve procedural success at this location.

\section{Acknowledgments}

Dr. Packer in the past 12 months has provided consulting services for Abiomed, Biosense Webster, Inc., Boston Scientific, CardioDX, CardioFocus, CardioInsight Technologies, Excerpta Medica, FoxP2 Medica LLC, InfoBionic, Inc., Johnson \& Johnson Healthcare Systems, Johnson \& Johnson, MediaSphere Medical, LLC, Medtronic CryoCath, OrthoMcNeill, Sanofi-Aventis, Siemens, St. Jude Medical, and Siemens AG, and received no personal compensation for these consulting activities. He receives research funding from the Biosense Webster, Boston Scientific/EPT, Endosense, EpiEP, EP Advocate, Medtronic CryoCath LP, Minnesota Partnership for Biotechnology and Medical Genomics/University of Minnesota, NIH, CardioFocus, Hansen Medical, Siemens P4D, St. Jude Medical, Siemens AcuNav, and Thermedical (EP Limited).

Dr. Friedman receives research support from Medtronic (grant administered by Mayo Clinic for investigator initiated study) and Biotronik; honoraria from Bard, Biotronik, Leadex, Sorin, Boston Scientific, and Helical Solutions; intellectual property rights from Bard EP, Medical Positioning, Inc., Aegis Medical, NeoChord, Preventice, and Sorin.

Dr. Asirvatham receives no significant honoraria and/or consulting for Abiomed, Atricure, Biotronik, Boston Scientific, Medtronic, Spectranetics, St. Jude, Sanofi-Aventis, Wolters Kluwer, Elsevier.

\section{Abbreviations}

$\begin{array}{ll}\text { AMC } & \text { aortic mitral continuity } \\ \text { AV } & \text { atrioventricular } \\ \text { ECG } & \text { electrocardiogram } \\ \text { EF } & \text { ejection fraction } \\ \text { EGM } & \text { electrogram } \\ \text { GCV-AIVV } & \text { great cardiac vein and the anterior interventricular vein } \\ \text { LPF } & \text { left posterior fascicle } \\ \text { LVEF } & \text { left ventricular ejection fraction } \\ \text { PP } & \text { prepotential } \\ \text { PVC } & \text { premature ventricular contractions } \\ \text { VA } & \text { ventricular arrhythmia }\end{array}$



VEGM
ventricular electrogram
VT
ventricular tachycardia

\section{References}

1. Ali H, Vitali-Serdoz L, Ferrero P, Pittalis M, Belotti G, Cappato R. An unusual case of permanent junctional reciprocating tachycardia: Successful ablation at the mitral annulus-aorta junction. $\mathbf{J}$ Interv Card Electrophysiol. 2008; 23:213-217. [PubMed: 18810623]

2. Chen J, Hoff PI, Rossvoll O, De Bortoli A, Solheim E, Sun L, Schuster P, Larsen T, Ohm OJ. Ventricular arrhythmias originating from the aortomitral continuity: an uncommon variant of left ventricular outflow tract tachycardia. Europace. 2012; 14:388-395. [PubMed: 21979993]

3. Dixit S, Gerstenfeld EP, Lin D, Callans DJ, Hsia HH, Nayak HM, Zado E, Marchlinski FE. Identification of distinct electrocardiographic patterns from the basal left ventricle: distinguishing medial and lateral sites of origin in patients with idiopathic ventricular tachycardia. Heart Rhythm. 2005; 2:485-491. [PubMed: 15840472]

4. Gonzalez MD, Contreras LJ, Jongbloed MR, Rivera J, Donahue TP, Curtis AB, Bailey MS, Conti JB, Fishman GI, Schalij MJ, Gittenberger-de Groot AC. Left atrial tachycardia originating from the mitral annulus-aorta junction. Circulation. 2004; 110:3187-3192. [PubMed: 15533857]

5. Kalbfleisch SJ, Rhodes TE. A rare case of permanent junctional reciprocating tachycardia ablated on the roof of the left atrium. J Cardiovasc Electrophysiol. 2013; 24:464-467. [PubMed: 22963110]

6. Kumagai K, Fukuda K, Wakayama Y, Sugai Y, Hirose M, Yamaguchi N, Takase K, Yamauchi Y, Takahashi A, Aonuma K, Shimokawa H. Electrocardiographic characteristics of the variants of idiopathic left ventricular outflow tract ventricular tachyarrhythmias. J Cardiovasc Electrophysiol. 2008; 19:495-501. [PubMed: 18266673]

7. Letsas KP, Efremidis M, Kollias G, Xydonas S, Sideris A. Electrocardiographic and electrophysiologic characteristics of ventricular extrasystoles arising from the aortomitral continuity. Cardiol Res Pract. 2011; 2011:864964. [PubMed: 21637720]

8. Otomo K, Azegami K, Sasaki T, Kawabata M, Hirao K, Isobe M. Successful catheter ablation of focal left atrial tachycardia originating from the mitral annulus aorta junction. Int Heart J. 2006; 47:461-468. [PubMed: 16823252]

9. Shehata M, Liu T, Joshi N, Chugh SS, Wang X. Atrial tachycardia originating from the left coronary cusp near the aorto-mitral junction: anatomic considerations. Heart Rhythm. 2010; 7:987991. [PubMed: 20230911]

10. Steven D, Roberts-Thomson KC, Seiler J, Inada K, Tedrow UB, Mitchell RN, Sobieszczyk PS, Eisenhauer AC, Couper GS, Stevenson WG. Ventricular tachycardia arising from the aortomitral continuity in structural heart disease: characteristics and therapeutic considerations for an anatomically challenging area of origin. Circ Arrhythm Electrophysiol. 2009; 2:660-666. [PubMed: 20009078]

11. Teh AW, Lee G, Kalman JM. A case of focal atrial tachycardia from the aortomitral continuity. J Cardiovasc Electrophysiol. 2010; 21:583-584. [PubMed: 20039987]

12. Yamada T, McElderry HT, Okada T, Murakami Y, Doppalapudi H, Yoshida N, Yoshida Y, Inden Y, Murohara T, Epstein AE, Plumb VJ, Kay GN. Idiopathic left ventricular arrhythmias originating adjacent to the left aortic sinus of valsalva: electrophysiological rationale for the surface electrocardiogram. J Cardiovasc Electrophysiol. 2010; 21:170-176. [PubMed: 19804552]

13. Asirvatham SJ. Correlative anatomy for the invasive electrophysiologist: outflow tract and supravalvar arrhythmia. J Cardiovasc Electrophysiol. 2009; 20:955-968. [PubMed: 19490263]

14. Gami AS, Noheria A, Lachman N, Edwards WD, Friedman PA, Talreja D, Hammill SC, Munger TM, Packer DL, Asirvatham SJ. Anatomical correlates relevant to ablation above the semilunar valves for the cardiac electrophysiologist: a study of 603 hearts. J Interv Card Electrophysiol. 2011; 30:5-15. [PubMed: 21161573]

15. Srivathsan KS, Bunch TJ, Asirvatham SJ, Edwards WD, Friedman PA, Munger TM, Hammill SC, Cha YM, Brady PA, Jahangir A, Bradley DJ, Rea RF, Packer DL, Shen WK. Mechanisms and 
utility of discrete great arterial potentials in the ablation of outflow tract ventricular arrhythmias. Circ Arrhythm Electrophysiol. 2008; 1:30-38. [PubMed: 19808391]

16. Szili-Torok T, van Malderen S, de Groot N. 'Born' with a 'dead'-end-tract resulting in arrhythmias in the aorto-mitral continuity: coincidence, causation, and 'commensuration'. Europace. 2012; 14:308-309. [PubMed: 22308091]

17. Tabatabaei N, Asirvatham SJ. Supravalvular arrhythmia: identifying and ablating the substrate. Circ Arrhythm Electrophysiol. 2009; 2:316-326. [PubMed: 19808482]

18. Gaztanaga L, Marchlinski FE, Betensky BP. Mechanisms of cardiac arrhythmias. Rev Esp Cardiol (Engl Ed). 2012; 65:174-185. [PubMed: 22192903]

19. Iinuma H, Sekiguchi A, Kato K. The response of digitalized canine ventricle to programmed stimulation: a study on triggered activity arrhythmias in the whole heart. Pacing Clin Electrophysiol. 1989; 12:1331-1346. [PubMed: 2476757]

20. Johnson N, Danilo P Jr, Wit AL, Rosen MR. Characteristics of initiation and termination of catecholamine-induced triggered activity in atrial fibers of the coronary sinus. Circulation. 1986; 74:1168-1179. [PubMed: 3769174]

21. Josephson, ME. Clinical cardiac electrophysiology. Techniques and interpretations. Riverwoods, IL: Lippincott Williams \& Wilkins; 2008.

22. Malfatto G, Rosen TS, Rosen MR. The response to overdrive pacing of triggered atrial and ventricular arrhythmias in the canine heart. Circulation. 1988; 77:1139-1148. [PubMed: 3359591]

23. Moak JP, Rosen MR. Induction and termination of triggered activity by pacing in isolated canine Purkinje fibers. Circulation. 1984; 69:149-162. [PubMed: 6689639]

24. Mohamed U, Skanes AC, Gula LJ, Leong-Sit P, Krahn AD, Yee R, Subbiah R, Klein GJ. A novel pacing maneuver to localize focal atrial tachycardia. J Cardiovasc Electrophysiol. 2007; 18:1-6. [PubMed: 17081203]

25. Waldo AL. From bedside to bench: entrainment and other stories. Heart Rhythm. 2004; 1:94-106. [PubMed: 15851125]

26. Yamada T, Kay GN. Optimal ablation strategies for different types of ventricular tachycardias. Nat Rev Cardiol. 2012; 9:512-525. [PubMed: 22641339]

27. Stevenson WG, Soejima K. Catheter ablation for ventricular tachycardia. Circulation. 2007; 115:2750-2760. [PubMed: 17533195]

28. Kadish AH, Buxton AE, Kennedy HL, Knight BP, Mason JW, Schuger CD, Tracy CM, Boone AW, Elnicki M, Hirshfeld JW Jr, Lorell BH, Rodgers GP, Weitz HH. ACC/AHA clinical competence statement on electrocardiography and ambulatory electrocardiography. A report of the ACC/AHA/ACP-ASIM Task Force on Clinical Competence (ACC/AHA Committee to Develop a Clinical Competence Statement on Electrocardiography and Ambulatory Electrocardiography). J Am Coll Cardiol. 2001; 38:2091-2100. [PubMed: 11738321]

29. Rautaharju PM, Surawicz B, Gettes LS, Bailey JJ, Childers R, Deal BJ, Gorgels A, Hancock EW, Josephson M, Kligfield P, Kors JA, Macfarlane P, Mason JW, Mirvis DM, Okin P, Pahlm O, van Herpen G, Wagner GS, Wellens H. AHA/ACCF/HRS recommendations for the standardization and interpretation of the electrocardiogram: part IV: the ST segment, T and U waves, and the QT interval: a scientific statement from the American Heart Association Electrocardiography and Arrhythmias Committee, Council on Clinical Cardiology; the American College of Cardiology Foundation; and the Heart Rhythm Society. Endorsed by the International Society for Computerized Electrocardiology. J Am Coll Cardiol. 2009; 53:982-991. [PubMed: 19281931]

30. Surawicz B, Childers R, Deal BJ, Gettes LS, Bailey JJ, Gorgels A, Hancock EW, Josephson M, Kligfield P, Kors JA, Macfarlane P, Mason JW, Mirvis DM, Okin P, Pahlm O, Rautaharju PM, van Herpen G, Wagner GS, Wellens H. AHA/ACCF/HRS recommendations for the standardization and interpretation of the electrocardiogram: part III: intraventricular conduction disturbances: a scientific statement from the American Heart Association Electrocardiography and Arrhythmias Committee, Council on Clinical Cardiology; the American College of Cardiology Foundation; and the Heart Rhythm Society. Endorsed by the International Society for Computerized Electrocardiology. J Am Coll Cardiol. 2009; 53:976-981. [PubMed: 19281930] 
31. Del Carpio Munoz F, Buescher T, Asirvatham SJ. Teaching points with 3-dimensional mapping of cardiac arrhythmias: taking points: activation mapping. Circ Arrhythm Electrophysiol. 2011; 4:e22-25. [PubMed: 21673021]

32. Tranum-Jensen J, Wilde AA, Vermeulen JT, Janse MJ. Morphology of electrophysiologically identified junctions between Purkinje fibers and ventricular muscle in rabbit and pig hearts. Circ Res. 1991; 69:429-437. [PubMed: 1860183]

33. Veenstra RD, Joyner RW, Rawling DA. Purkinje and ventricular activation sequences of canine papillary muscle. Effects of quinidine and calcium on the Purkinje-ventricular conduction delay. Circ Res. 1984; 54:500-515. [PubMed: 6722999]

34. Kurosawa H, Becker AE. Dead-end tract of the conduction axis. Int J Cardiol. 1985; 7:13-20. [PubMed: 4055131]

35. McGuire MA, de Bakker JM, Vermeulen JT, Moorman AF, Loh P, Thibault B, Vermeulen JL, Becker AE, Janse MJ. Atrioventricular junctional tissue. Discrepancy between histological and electrophysiological characteristics. Circulation. 1996; 94:571-577. [PubMed: 8759104]

36. Wit AL, Fenoglio JJ Jr, Wagner BM, Bassett AL. Electrophysiological properties of cardiac muscle in the anterior mitral valve leaflet and the adjacent atrium in the dog. Possible implications for the genesis of atrial dysrhythmias. Circ Res. 1973; 32:731-745. [PubMed: 4715195]

37. Anderson RH, Boyett MR, Dobrzynski H, Moorman AF. The anatomy of the conduction system: implications for the clinical cardiologist. J Cardiovasc Transl Res. 2013; 6:187-196. [PubMed: 23242580]

38. Wit AL, Cranefield PF. Triggered activity in cardiac muscle fibers of the simian mitral valve. Circ Res. 1976; 38:85-98. [PubMed: 812612] 


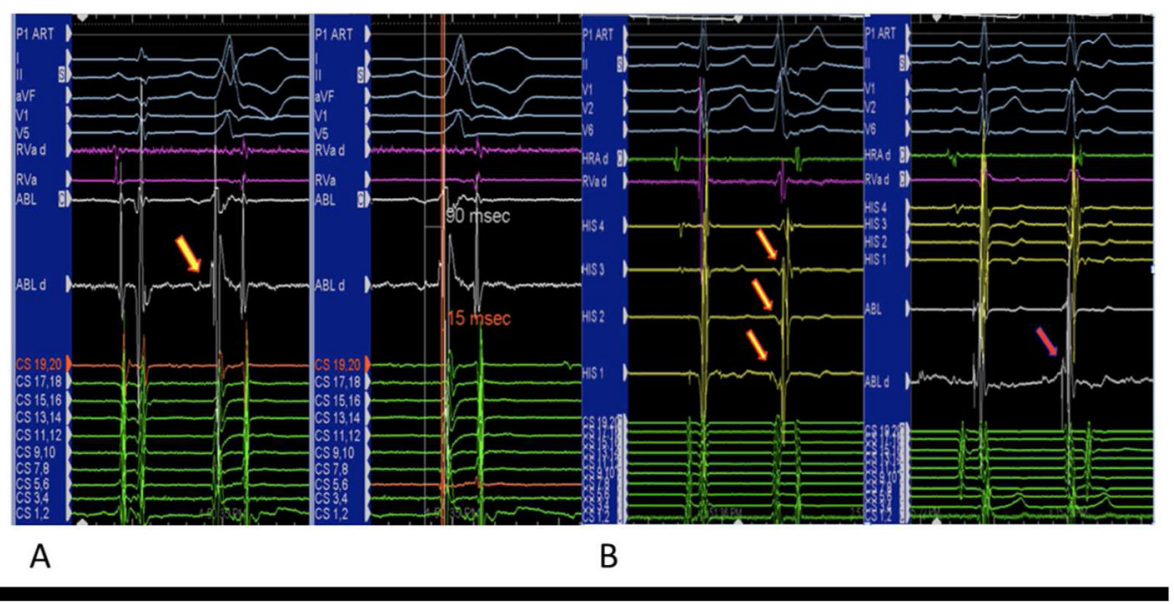

Figure 1.

Panel A - Intracardiac recording showing a PP, as indicated by the yellow arrow. The prepotential was noted preceding the local VEGM and surface QRS during spontaneous ectopy, with the PP-QRS being $90 \mathrm{~ms}$ and VEGM-QRS being $15 \mathrm{~ms}$.

Panel B - A premature ventricular complex with relatively narrow QRS was associated with negative $\mathrm{V}-\mathrm{H}$ interval and distal to proximal activation sequence of the His bundle as shown by the yellow arrows. At the ablation site, PP, which is indicated by the red arrow, was found ahead of the VEGM and the onset of the surface QRS.

PP - prepotential; VEGM - ventricular electrogram 


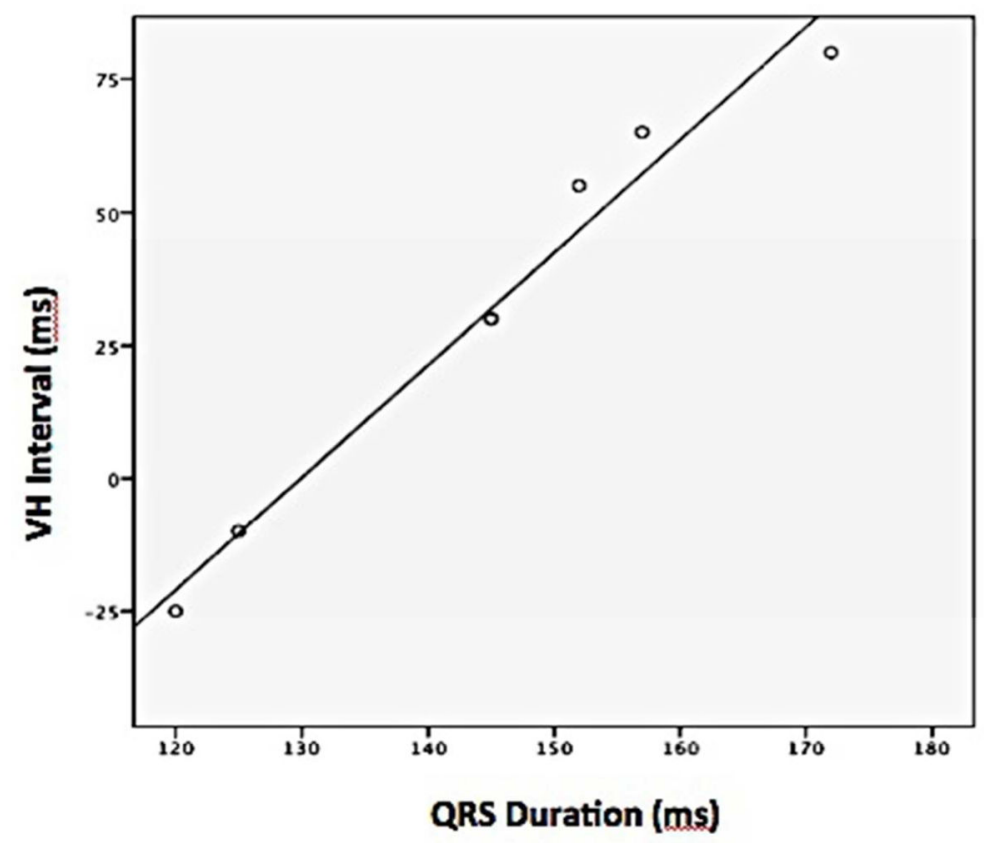

Figure 2.

Relationship between VH interval and QRS duration of ventricular arrhythmias originating from the aortomitral continuity associated with prepotentials. 
Table 1

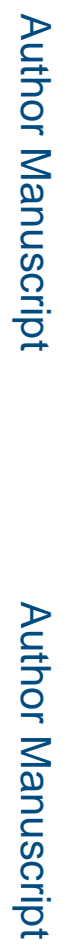

Baseline clinical characteristics.

\begin{tabular}{|l|c|c|c|}
\hline & Pre-ablation & Post-ablation & P value \\
\hline Symptoms (n, \%) & & & \\
\hline Chest discomfort $^{*}$ & $9(42.9)$ & $1(4.8)$ & $<0.01$ \\
\hline Fatigue $^{*}$ & $15(71.4)$ & $2(9.5)$ & $<0.001$ \\
\hline Palpitations $^{*}$ & $14(66.7)$ & $5(23.8)$ & $<0.01$ \\
\hline Lightheadedness/presyncope $^{*}$ & $12(57.1)$ & $9(42.9)$ & 0.03 \\
\hline Syncope & $2(9.5)$ & $0(0)$ & 0.48 \\
\hline PVC burden ${ }^{*}(\%)$ & $23.4 \pm 13.1$ & $2.2 \pm 3.4$ & $<0.001$ \\
\hline LVEF $(\%)$ & $50.8 \pm 12.2$ & $51.9 \pm 12.6$ & 0.52 \\
\hline LVEDD $(\mathrm{mm})$ & $53.5 \pm 5.2$ & $52.8 \pm 5.0$ & 0.44 \\
\hline & & & \\
P $<0.05$ & & &
\end{tabular}

PVC - premature ventricular complex; LVEF - left ventricular ejection fraction; LVEDD - left ventricular end-diastolic diameter 
Table 2

Comparison of clinical and electrophysiological characteristics of patients with and without pre-potentials.

\begin{tabular}{|l|c|c|c|}
\hline & $\begin{array}{c}\text { With PP } \\
\mathbf{N = 1 3}\end{array}$ & $\begin{array}{c}\text { Without PP } \\
\mathbf{N = 8}\end{array}$ & P value \\
\hline Age (years) & $50.0 \pm 13.4$ & $58.4 \pm 12.4$ & 0.17 \\
\hline Sex (male, \%) & $6(46.2)$ & $5(62.5)$ & 0.66 \\
\hline Symptoms (n, \%) & & & \\
\hline Chest discomfort & $5(38.5)$ & $4(50)$ & 0.67 \\
\hline Fatigue & $10(76.9)$ & $5(62.5)$ & 1.00 \\
\hline Palpitations & $9(69.2)$ & $5(62.5)$ & 1.00 \\
\hline Lightheadedness/presyncope & $6(46.2)$ & $6(75)$ & 0.37 \\
\hline Syncope & $0(0)$ & $2(25)$ & 0.13 \\
\hline Non-sustained VT & $6(46.2)$ & $3(37.5)$ & 1.00 \\
\hline Sustained VT & $0(0)$ & $1(12.5)$ & 0.38 \\
\hline PVC burden* $(\%)$ & $26.1 \pm 10.9$ & $14.9 \pm 10.1$ & 0.03 \\
\hline LVEF $(\%)$ & $54.8 \pm 9.7$ & $48.1 \pm 17.1$ & 0.27 \\
\hline LVEDD (mm) & $53.2 \pm 4.7$ & $53.6 \pm 5.8$ & 0.84 \\
\hline LVEF <50\% (n, \%) & $3(37.5)$ & $4(30.8)$ & 1.00 \\
\hline$>1$ VA morphology at AMC (n, \%) & $4(30.8)$ & $0(0)$ & 0.13 \\
\hline V-H interval during VA (ms) & $32.1 \pm 38.6$ & $76.3 \pm 11.1$ & 0.06 \\
\hline VA ablated at other regions* $(\mathrm{n}, \%)$ & $1(7.7)$ & $4(50)$ & 0.047 \\
\hline VEGM-QRS at AMC* (ms) & $9.0 \pm 28.5$ & $33.1 \pm 8.8$ & 0.03 \\
\hline Pacemap score* (n/12) & $8.7 \pm 1.6$ & $11.4 \pm 0.8$ & 0.001 \\
\hline
\end{tabular}

PP - prepotential; VT - ventricular tachycardia; PVC - premature ventricular complex; LVEF - left ventricular ejection fraction; LVEDD - left ventricular end-diastolic diameter; VA - ventricular arrhythmia; AMC - aortomitral continuity; VEGM - ventricular electrogram 


\begin{tabular}{|c|c|c|c|c|c|c|c|c|c|c|c|}
\hline \multirow{8}{*}{ 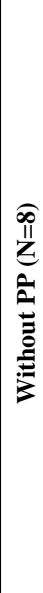 } & $\stackrel{2}{2}$ & ర్ర & $\hat{i}$ & $\simeq$ & $\bar{\simeq}$ & $\simeq$ & $\approx$ & $\simeq$ & $\simeq$ & $\simeq$ & $\simeq$ \\
\hline & 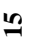 & $\underline{6}$ & 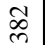 & $\simeq$ & $\widetilde{\simeq}$ & $\simeq$ & $\tilde{\approx}$ & $\tilde{z}$ & $\hat{\varkappa}$ & $\approx$ & $\hat{\approx}$ \\
\hline & $=$ & さे & $\stackrel{\vartheta}{\Rightarrow}$ & $\simeq$ & $\bar{\simeq}$ & $\frac{\mathscr{c}}{2}$ & $\mathscr{I}$ & $\approx$ & $\simeq$ & $\simeq$ & $\simeq$ \\
\hline & $a$ & 过 & ô & $\simeq$ & $\bar{z}$ & $\simeq$ & $\simeq$ & $\simeq$ & $\simeq$ & $\simeq$ & $\simeq$ \\
\hline & $\infty$ & $\underline{\Omega}$ & ธి & $\simeq$ & $\bar{\simeq}$ & $\simeq$ & $\tilde{\approx}$ & $\tilde{\approx}$ & $\tilde{n}$ & $\tilde{\approx}$ & $\tilde{\approx}$ \\
\hline & + & $\underline{2}$ & $\stackrel{n}{f}$ & $\simeq$ & $\bar{z}$ & $\stackrel{\approx}{\sigma}$ & $\approx$ & $\tilde{\approx}$ & $\simeq$ & $\simeq$ & $\simeq$ \\
\hline & $m$ & さ & $\stackrel{\curvearrowright}{\curvearrowright}$ & $\simeq$ & $\bar{z}$ & $\simeq$ & $\hat{\approx}$ & $\simeq$ & $\simeq$ & $\hat{\approx}$ & $\hat{\simeq}$ \\
\hline & $\sim$ & I & $\stackrel{\circledast}{\Im}$ & $\simeq$ & $\bar{\alpha}$ & $\simeq$ & $\tilde{\approx}$ & $\tilde{2}$ & $\tilde{\imath}$ & $\tilde{\approx}$ & $\tilde{\approx}$ \\
\hline
\end{tabular}

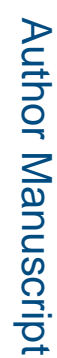

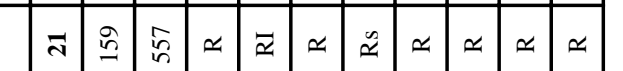

